\title{
Editorial
}

\section{The fantastic year of 2010 - and the really hot topic: breast-feeding}

\section{Impact factor and size}

This year has been a good one for our journal. We have increased our impact factor substantially, to the current $2 \cdot 749$, from the 2008 impact factor of $2 \cdot 132$. We have had more papers submitted than ever, and we are sending you a much heavier printed issue after increasing the number of pages.

\section{Editorial board and the people behind the scene}

The Editorial Board has had some good additions of hardworking colleagues and among the Deputy Editors we can now find Marilyn Tseng from California Polytechnic State University, USA, who has been with the journal for several years. Three recently added deputies are Dr Allison Hodge from University of Melbourne, Australia; Dr Irja Haapala, University of Eastern Finland; and Prof Geraldine McNeill, University of Aberdeen and the Rowett Institute of Nutrition and Health. A large number of new Associate Editors have been invited, representing new areas as well as a more total global coverage.

At the Nutrition Society, Catherine Jackson, Lalitha Weeks and Julie Hickman are doing a great day-to-day job with the journal. The publications officer Dr David Bender is always a reliable source of guidance and support in journal matters. At Cambridge University Press, Carol Miller, Katy Christomanou, Kathryn Wilson and Rebecca Curtis are doing a lot of good work for the journal; as is Gill Watling, our freelance copyeditor and proof-reader.

\section{In this issue}

In the current issue you will find MANY papers on breastfeeding. There is one letter to the editor from Hermann Kalhoff and Katharina Dube ${ }^{(1)}$ about iron deficiency among fully breast-fed children and a response to this letter from Michael Kramer ${ }^{(2)}$. You can also find papers regarding determinants for breast-feeding and exclusive breastfeeding $^{(3,4)}$ and breast-feeding prevalence ${ }^{(5,6)}$. The paper by Häggkvist et $a l .{ }^{(5)}$ represents extremely interesting material from the gigantic Norwegian Mother and Child Cohort Study (MoBa), covering almost 30000 mothers and children. Not surprisingly, the results from this study show that supplementation during the first week, breast-feeding problems and Caesarian delivery are associated with early cessation of full breast-feeding.
This issue also has a number of papers covering infant and young child feeding, ranging from developing a dietlifestyle quality index for young children ${ }^{(7)}$ to infant feeding practices among HIV-positive women in Tanzania ${ }^{(8)}$ and consequences of early fruit and vegetable feeding practices in the $\mathrm{UK}^{(9)}$.

Thank you to all authors, Cambridge University Press, The Nutrition Society and editors. The busy year of 2010 could only have been made so successful with the support from all of you. Thank you and Happy New Year!

\author{
Agneta Yngve \\ Editor-in-Chief \\ Marilyn Tseng \\ Allison Hodge \\ Geraldine McNeill \\ Irja Haapala \\ Deputy Editors
}

\section{References}

1. Kalhoff H \& Dube K (2010) Iron deficiency in infants fully breastfed for 6 months may not be transitory: first observations during the second half of infancy (letter). Public Health Nutr 13, 2130-2131.

2. Kramer MS (2010) Response to Drs Kalhoff and Dube (letter). Public Health Nutr 13, 2131-2132.

3. Bonet M, Blondel B \& Khoshnood B (2010) Evaluating regional differences in breast-feeding in French maternity units: a multi-level approach. Public Health Nutr 13, 1946-1954.

4. Kristiansen AL, Lande B, Øverby NC et al. (2010) Factors associated with exclusive breast-feeding and breastfeeding in Norway. Public Health Nutr 13, 2087-2096.

5. Häggkvist AP, Brantsæter AL, Grjibovski AM et al. (2010) Prevalence of breast-feeding in the Norwegian Mother and Child Cohort Study and health service-related correlates of cessation of full breast-feeding. Public Health Nutr 13, 2076-2086.

6. Andersson N, Paredes-Solís S, Legorreta-Soberanis J et al. (2010) Breast-feeding in a complex emergency: four linked cross-sectional studies during the Bosnian conflict. Public Health Nutr 13, 2097-2104.

7. Manios Y, Kourlaba G, Grammatikaki E et al. (2010) Development of a diet-lifestyle quality index for young children and its relation to obesity: the Preschoolers Diet-Lifestyle Index. Public Health Nutr 13, 2000-2009.

8. Young SL, Israel-Ballard KA, Dantzer EA et al. (2010) Infant feeding practices among HIV-positive women in Dar es Salaam, Tanzania, indicate a need for more intensive infant feeding counselling. Public Health Nutr 13, 2027-2033.

9. Coulthard H, Harris G \& Emmett P (2010) Long-term consequences of early fruit and vegetable feeding practices in the United Kingdom. Public Health Nutr 13, 2044-2051. 